\title{
TOUGH CHOICES: TENOFOVIR, TENDERS AND TREATMENT
}

\author{
Nathan Ford, $B S c, D H A$ \\ Médecins Sans Frontières, Johannesburg \\ Andy Gray, MSc (Pharm), FPS (SA) \\ Department of Therapeutics and Medicines Management, Nelson R Mandela School of Medicine, University of KwaZulu-Natal, Durban \\ W D Francois Venter, $F C P(S A)$ \\ HIV Management Cluster, Reproductive Health and HIV Research Unit, University of the Witwatersrand, Johannesburg
}

Scaling up of antiretroviral therapy (ART) in developing countries would not have been possible without market competition, which has driven down the price of standard first-line antiretroviral (ARV) drugs from more than US\$12 000 per person/year in 2000 to US\$99 today. However, access to newer, second-line ARVs remains largely restricted to originator (patented) drugs. This causes significant challenges in countries where access to newer medicines is becoming increasingly important as programmes mature and face challenges related to drug toxicity and resistance. ${ }^{1}$ Toxicity in particular has emerged as a major reason for individual drug switches and regimen changes, and is strongly implicated in decreasing adherence.

This article focuses on international efforts to reduce the price of tenofovir, and outlines the implications of these dynamics for South Africa.

\section{PATENT RIGHTS AND WRONGS}

Under international trade rules, patent protection for pharmaceuticals lasts 20 years. During this period, competitors are excluded from the market, which generally results in medicine prices that far exceed production costs. ${ }^{2}$ Patent protection is particularly widespread in developing countries with strong pharmaceutical manufacturing capacity, including South Africa. ${ }^{3}$

The main defence of the patent system is based on the argument that it acts as an incentive for investing in research and development. In order to benefit from patent protection, manufacturers need to demonstrate that they have contributed sufficiently to the drug innovation process. In the field of HIV/AIDS, the public sector - principally universities and large publicly funded government research organisations - have contributed significantly, and sometimes entirely, to the research and development of many key ARVs. Abacavir, didanosine, stavudine, zalcitabine, zidovudine and the concept of protease inhibition have all received substantial public funding in their discovery and development. ${ }^{4,5}$

Public interest and patient groups have successfully challenged the legitimacy of a number of ARV patents, based on the fact that patent holders did nothing significantly inventive to deserve a monopoly. In Thailand, Bristol-Myers Squibb's patent for didanosine was overturned on the grounds that the patent holder manipulated the details of the patent claim, and the fact that most of the research and development was done by the US National Institutes of Health. ${ }^{6}$ In India and Thailand, civil society groups managed to successfullyblock a patent application by GlaxoSmithKline for the combination zidovudine+lamivudine on the grounds that simply combining two known and already patented drugs was not sufficiently inventive to warrant an extended monopoly. In South Africa, the purchasing of generic stavudine was made possible because of a challenge to the licensing agreement between Bristol-Myers Squibb and the patent owner, Yale University. ${ }^{8}$ Each of these initiatives has led to significant cost savings, as is clearly demonstrated by the precipitate fall in the price of branded stavudine in South Africa, from more than US\$1 539 per adult patient/ year in 2000 to less than US\$77 in 2008. Generic versions cost even less.

\section{CHALLENGING THE TENOFOVIR MONOPOLY}

Tenofovir disoproxil fumarate (TDF) is a desirable ARV because it is regarded as safe, requires relatively limited toxicity monitoring, and is administered once daily. At the end of January 2008, the US Patent and Trademark Office revoked four key patents held by Gilead Sciences for TDF. This followed a challenge by a US public interest organisation (the Public Patent Foundation) that showed that TDF was already a known substance by the time Gilead applied for the patents. ${ }^{9}$ (Much of the research work was done by the Academy of Sciences of the Czech Republic and the Catholic University in Leuven, Belgium. Emtricitabine, which is partnered with TDF in a once-a-day dosage form, Truvada, was similarly discovered by public researchers at Emory University.) Similar patent challenges have been filed by civil society groups in India, and Thailand is expected to follow suit.

Patent challenges have been raised in part because of the unreasonably high cost and significant variation in pricing of TDF. For example, Brazil, South Africa and Thailand have very similar gross domestic products, but the price of TDF 
tender will allow for its procurement. It is also not clear whether a generic manufacturer, which holds neither patent nor agreement with the patent holder, will be able to enter the process, even if that generic production is entirely consistent with intellectual property law.

Two other clauses in the 2004 request for proposals relate to registration and are standard for all medicine tenders:

3.1 Bidders offering medicines which require registration in terms of the Medicines and Related Substances Act, (Act 101 of 1965 as amended), must be in possession of valid registration certificates, issued in terms of the said Act at the closing date and time of the request for proposal/ quotation, and must comply with the conditions under which the medicines have been registered. Copies of registration certificates for drugs offered must be supplied with the bid document at the closing date and time of the request for proposal/quotation.

3.2 Bidders offering medicines must supply proof of positive GMP status with the Medicines Control Council which must be submitted with the bid document at the closing date and time of the request for proposal/quotation.

The registration of generic TDF products may therefore present a second obstacle to procuring more affordable versions of this highly desirable ARV. TDF was only registered in South Africa in mid-2007, even though it has been registered in the USA since 2001 and in Europe since 2002. The registration dossier was finally submitted to the South African Medicines Control Council early in 2006. Even if affordable, quality-assured, generic versions of TDF become available this year, the registration of these products for use in South Africa may take an unnecessarily long time. The popular 'all-in-one' single tablet coformulation of tenofovir/emtricitabine/efavirenz, which is widely used in developed countries as one of the safest and most convenient combinations, will probably take years to be registered in South Africa because of the complexity of having two pharmaceutical companies owning different patents.

That generic versions are needed is amply demonstrated by the lack of price differentials between the tender prices and private sector single-exit prices for products only available from brand manufacturers. Ideally, the volumes guaranteed by large-scale programmes in the State sector and the relatively simple product delivery processes should mean that the State should enjoy significant cost reductions. This has not uniformly been the case. For example, efavirenz (EFV) $600 \mathrm{mg}$ tablets are sold to the South African public and private sectors at the same price (US\$238 per person/ year). In contrast, nevirapine (NVP) $200 \mathrm{mg}$ tablets are provided to the State at US\$74.50 per person/year by a generic manufacturer, which sells the same product in the private sector for US\$276.84. The branded version sells to the private sector for US\$983. Nevirapine $50 \mathrm{mg} / 5 \mathrm{ml}$ suspension provides an object lesson in the consequences of insisting on the existence of concluded voluntary licences at the time of tender submission. The State currently purchases a bottle at US\$25.86, whereas the lowest-priced licensed generic sells to the private sector at US\$13.13. While a tender provides a measure of stability over time, it may also limit the ability of the State to take advantage of new clinical evidence and/or new generic entrants.

\section{CONCLUSIONS}

ARV scale-up in the developing world was made possible because of a simple, affordable first-line regimen using public health principles. As HIV treatment programmes mature, the need for newer medicines to overcome toxicity and resistance is becoming increasingly urgent. Faced with rising treatment costs, a number of developing countries have taken strong action against the monopolies on key ARV patents, resulting in significant cost savings.

For South Africa, broader access to TDF has the potential to simplify treatment by offering a more favourable sideeffect profile, an issue that is particularly important in facilitating the provision of care at the primary care level. Further potential for simplification is presented by the use of TDF in the once-a-day combination of tenofovir/ emtricitabine/efavirenz (and potentially tenofovir/ lamivudine/nevirapine).

Internationally, the cost of TDF is set to fall significantly in the coming months. The price that South Africa will pay will depend on whether the tender process will allow for the inclusion of new, unpatented medicines and how quickly these new products can be registered. Neither of these issues is immutable: they are simple matters of policy choice.

Dr Venter acknowledges support from PEPFAR.

REFERENCES

Chien CV. HIV/AIDS drugs for Sub-Saharan Africa: how do brand and generic supply compare? PLOS ONE 2007; 2(3): e278.

2. Westerhaus $M$, Castro $A$. How do intellectual property law and international trade agreements affect access to antiretroviral therapy? PLoS Med 2006; 8: 1230-1236. Attaran A, Gillespie-White L. Do patents for antiretroviral drugs constrain access to AIDS treatment in Africa? JAMA 2001; 286(15): 1886-1892.

4. Chirac $P$, von Schoen-Angerer $T$, Kasper $T$, Ford N. AIDS: patent rights versus patient's rights. Lancet 2000; 356: 502

5. Chokshi $D$, Rajkumar R. Leveraging university research to advance global health JAMA 2007; 298: 1934-1936.

6. Ford N, Wilson D, Bunjumnong $\mathrm{O}$, von Schoen-Angerer T. The role of civil society in protecting public health over commercial interests: lessons from Thailand. Lancet 2004; 363: 560-563

7. Ford N, Wilson D, Costa Chaves G, Lotrowska M, Kijtiwatchakul K. Sustaining access to antiretroviral therapy in developing countries: lessons from Brazil and Thailand. AIDS 2007; 21(Suppl 4): S21-S29.

8. Chokshi D. Improving access to medicines in poor countries: The role of universities. PLoS Med 2006; 6: 723-726

9. Beasley D. US patent office rejects Gilead Viread patents. Reuters, 23 January 2008.

10. Untangling the Web of Price Reductions: A Pricing Guide for the Purchase of ARVs for Developing Countries. 10th ed. Geneva: Médecins Sans Frontiéres, 2007.

11. Gilead Sciences and Aspen Pharmacare sign letter of intent to establish non exclusive licensing and distribution agreement for antiretrovirals truvada and viread in developing world countries. Business Wire, 25 April 2005. http:// findarticles.com/p/articles/mi_m0EIN/is_2005_April_25/ai_n13650816 laccessed 10 February 2008).

12. Guidelines for the Use of Antiretroviral Agents in HIV-1-infected Adults and Adolescents. Washington, DC: United States Department of Health and Human Services, 2006.

13. Regensberg L, Whitelaw C, eds. Aid for AIDS Guideline. 6th ed. Howard Place: Aid for AIDS, 2007.

14. Model Essential Medicines List. 15th ed. Geneva: World Health Organization, 2007.

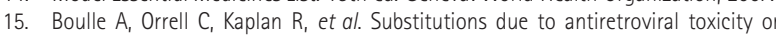
contraindication in the first 3 years of antiretroviral therapy in a large South African cohort. Antiviral Therapy 2007; 12: 753-760.

16. Request for proposals/quotation. RT71-2004MF. The supply of antiretroviral drugs for the Department of Health's Comprehensive HIV and AIDS Care, Management and Treatment Plan. Pretoria: State Tender Board, 2004. 